\title{
Evaluation of HI-6 oxime: potential use in protection of human acetylcholinesterase inhibited by antineoplastic drug irinotecan and its cyto/genotoxicity in vitro
}

\author{
Božica Radić ${ }^{1}$, Ana Lucić Vrdoljak ${ }^{1}$, Davor Želježić ${ }^{1}$, Nino Fuchs ${ }^{2}$, Suzana Berend ${ }^{1}$ \\ and Nevenka Kopjar ${ }^{1 凶}$ \\ ${ }^{1}$ Institute for Medical Research and Occupational Health, Zagreb, Croatia; ${ }^{2}$ Medical School, \\ University of Zagreb, Zagreb, Croatia
}

Received: 03 March, 2007; revised: 06 June, 2007; accepted: 01 August, 2007 available on-line: 23 August, 2007

\begin{abstract}
The function of acetylcholinesterase (AChE) is the rapid hydrolysis of the neurotransmitter acetylcholine $(\mathrm{ACh})$, which is involved in the numerous cholinergic pathways in both the central and the peripheral nervous system. Therefore, AChE measurement is of high value for therapy management, especially during the course of intoxication with different chemicals or drugs that inhibit the enzyme. Pyridinium or bispyridinium aldoximes (oximes) are able to recover the activity of the inhibited enzyme. Since their adverse effects are not well elucidated, in this study the efficiency of HI-6 oxime in protection and/or reactivation of human erythrocyte AChE inhibited by the antineoplastic drug irinotecan as well as its cyto/genotoxicity in vitro were investigated. HI-6 was effective in protection of AChE and increased its activity up to $30 \%$; the residual activity after irinotecan inhibition was $7 \%$. Also, it reactivated the enzyme previously inhibited by $50 \%$ irinotecan $(4.6 \mu \mathrm{g} / \mathrm{ml})$ applied at $1 / 4$ of the $\mathrm{IC}_{50}$ value. The tested concentrations of HI-6 exhibited acceptable genotoxicity towards white blood cells, as estimated by the alkaline comet assay, DNA diffusion assay and cytogenetic endpoints (structural chromosome aberrations and cytokinesis-block micronucleus assay). The results obtained warrant the further investigation of HI-6 in vivo, as well as its development for possible application in chemotherapy.
\end{abstract}

Keywords: HI-6, acetylcholinesterase, protection, reactivation, irinotecan, comet assay, apoptosis, chromosome aberrations, micronuclei

\section{INTRODUCTION}

The best-characterised function of acetylcholinesterase (AChE; EC 3.1.1.7) is the rapid hydrolysis of the neurotransmitter acetylcholine (ACh) at cholinergic synapses (Taylor \& Radić, 1994; Massoulié et al., 1999), which is involved in the numerous cholinergic pathways in both the central and pe- ripheral nervous system. Consequently, inhibition of AChE results in severe cholinergic toxic signs caused by increased concentration of $\mathrm{ACh}$ at cholinergic nerve-nerve and nerve-muscle synapses (Somani \& Romano, 2001). Muscular and nerve AChE are only present in the synaptic cleft and cannot be measured directly. Since erythrocyte AChE has a similar structure as the synaptic enzyme, it appears to be a

\footnotetext{
Corresponding author: Nevenka Kopjar, Institute for Medical Research and Occupational Health, Mutagenesis Unit, Ksaverska c. 2, HR-10000 Zagreb, Croatia; tel. (385) 14673 188; Fax. (385) 14673 303; e-mail: nkopjar@imi.hr Abbreviations: ACh, acetylcholine; AChE, acetylcholinesterase; ATCh, acetylthiocholine iodide; BN, binucleated cells; CA, chromosome aberration; CBMN, cytochalasin-blocked micronucleus assay; CBPI cytokinesis-block proliferation index; CPT-11, 7-ethyl-10-[4-(1-piperidino)-1-piperidino]carbonyloxycamptothecin; DTNB, 5,5'-dithio-bis(2-nitrobenzoic acid); HI6, [(1-(2-hydroxyiminomethylpyridinium)-3-(4-carbamoylpyridinium)-2-oxapropane dichloride)]; $\mathrm{IC}_{50}$, the concentration of the test compound, which inhibits $50 \%$ of $\mathrm{AChE}$ activity; $\mathrm{LD}_{50}$, acute toxicity based on $24 \mathrm{~h}$ mortality rates; LMP, low melting point; $\mathrm{MN}$, micronuclei; $\mathrm{NMP}$, normal melting point; $\mathrm{P}_{50}$, the antidote concentration-allowing AChE to preserve $50 \%$ of normal activity in the presence of inhibitor; $\mathrm{Pp}$, protective potency; $\mathrm{R}_{50}$, a concentration that yielded $50 \%$ enzyme reactivation.
} 
suitable model to reflect the various reactions at the synaptic site (Mortensen et al., 1998). Therefore, its measurement is of high value for therapy management, especially during the course of intoxication with different chemicals or drugs that inhibit the activity of the enzyme.

Clinical studies indicate the possibility of acute cholinergic side effects after intravenous administration of a new broad-spectrum anticancer drug, irinotecan (7-ethyl-10-[4-(1-piperidino)-1-piperidino] carbonyloxycamptothecin; CPT-11) (Grisaru et al., 1999; Morton et al., 1999), which, on the basis of in vitro experimental findings, have been ascribed to a direct blockade of AChE (Dodds \& Rivory, 1999; Hyatt et al., 2005). This drug has shown remarkable antitumor activity in the treatment of a variety of solid tumors. However, as with all cytotoxic chemotherapeutic agents, severe toxicity is frequently seen with irinotecan administration. The principal doselimiting toxicity of irinotecan is diarrhoea. It can cause either acute diarrhoea related to a cholinergic surge from inhibition of AChE (Gandia et al., 1993; Abigerges et al., 1994; Bugat et al., 1994; Petit et al., 1997; Hyatt et al., 2005), or a delayed diarrhoea syndrome, which is possibly related to the accumulation of an active metabolite of irinotecan in the bowel (Hecht, 1998). While the cholinergic syndrome is not life-threatening, it is very unpleasant for the individual and the patient requires constant monitoring during drug infusion (Gandia et al., 1993). Since this syndrome is associated with high dose irinotecan administration, measures to prevent and reduce the side effects associated with irinotecan are currently being explored (Furman et al., 2003; Waadkins et al., 2004).

Current evidence indicates that atropine is favorable in the management of acute cholinergic syndrome (Rothenberg et al., 1993). Namely, muscarinic symptoms as nausea, vomiting, diarrhoea and bowel movements can be stopped by its administration. Unfortunately, the available literature indicates that systematic adverse reactions to atropine are possible as well. Therefore, development of better protective compounds is needed. There are two types of adverse reactions to atropine: toxic (atropine toxicity) and allergic $\left(\mathrm{O}^{\prime}\right.$ Connor \& Mumma, 1985; Agiulera et al., 1988). The toxic reaction to atropine results from its anti-cholinergic action and includes a variety of peripheral and central manifestations. This toxic effect may occur at the usual therapeutic doses (Economacos \& Kanakis, 1981). Although cases of severe systemic reaction to atropine are very rare, it is important to identify patients allergic to atropine and to provide treatment regiments with alternative drugs.

Derivatives from the group of bis-pyridinium aldoximes (called oximes), such as HI-6 [(1-(2-hydro- xyiminomethylpyridinium)-3-(4-carbamoylpyridinium)-2-oxapropane dichloride)] are employed for the protection/reactivation of inhibited AChE. The mechanism of action of HI- 6 as a therapeutic component is clear now. It reactivates AChE inhibited by organophosphorus agents and may also have beneficial antinicotinic effects (Tattersal, 1983; Sheridan et al., 2000). Also, HI-6 can be highly effective in restoring some active AChE where the nicotinic effects of excessive $\mathrm{ACh}$ are not antagonized by atropine (Jonson et al., 2000).

According to the exceptional properties of HI-6, it seems reasonable to investigate the potential use of this oxime in protection of AChE inhibited by some antineoplastic drugs (US patent 5916903) too. Taking into account the assumption by Gandia et al. (1993), that the mechanism of cholinergic syndrome induced by irinotecan might be ascribed to a direct stimulation of nicotinic autonomic ganglia, we attempted here to investigate the use of HI-6 oxime to protect or reactivate AChE inhibited by irinotecan in vitro. Since in drug research it is desirable to find not only the most active, but also the least toxic substances, we wanted to assess the toxicity of HI-6 in the dose range used for effective protection/reactivation of inhibited AChE. In order to estimate the potential cyto/genotoxic effects of HI-6 in human peripheral blood leukocytes, a variety of assays were used: alkaline comet assay, DNA diffusion assay, analysis of structural chromosome aberrations and cytochalasin-block micronucleus assay.

\section{MATERIAL AND METHODS}

Blood sampling. Blood sample was obtained from a healthy female donor (age 37 years, nonsmoker) who gave an informed consent for participation in the study. The donor had not been exposed to diagnostic or therapeutic irradiations or to known genotoxic chemicals for a year before blood sampling. Venous blood $(40 \mathrm{ml})$ was collected under sterile conditions in heparinised vacutainer tubes (Becton Dickinson) containing lithium heparin as anticoagulant.

Enzyme assay and preparation. The activity of AChE was measured spectrophotometrically according to the Ellman procedure with the thiol reagent DTNB (final concentration $0.30 \mathrm{mmol} / \mathrm{l}$ ) (Ellman et al., 1961). All experiments were done in 0.1 $\mathrm{mol} / 1$ phosphate buffer, $\mathrm{pH} 7.4$, and enzyme activities were measured in the presence of $1.0 \mathrm{mmol} / \mathrm{l}$ acetylthiocholine iodide (ATCh) as substrate at $37^{\circ} \mathrm{C}$. Intact native human erythrocytes were used as the source of AChE; the final dilution during enzyme assay was 600 -fold. The reaction was performed in 
<smiles>NC(=O)c1cc[n+](COC[n+]2ccccc2/C=N/O)cc1</smiles>

HI-6

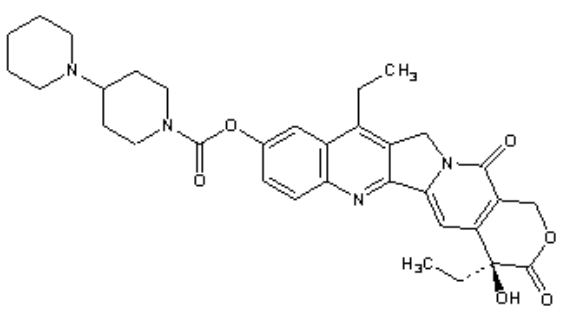

IRINOTECAN

Figure 1. Structural formulas of HI-6 and irinotecan.

the total volume of $3.0 \mathrm{ml}$. The increase in absorbance was read at $412 \mathrm{~nm}$ at $15 \mathrm{~s}$ intervals against a blank that contained the erythrocytes suspended in buffer and DTNB. All spectrophotometric measurements were performed using a CECIL 1000 spectrometer with temperature controller.

Chemicals and reagents. The structure of the studied oxime HI-6 and of irinotecan is given in Fig. 1. HI-6 was synthesized in Bosnalijek, Sarajevo (Bosnia and Herzegovina). It was kept at room temperature and was dissolved in sterile injection water immediately before use. Concentrations of HI- 6 tested for the cyto/genotoxicity corresponded to $1 / 4 \mathrm{LD}_{50}$ $\mathrm{IC}_{50}, \mathrm{P}_{50}$ and a concentration that yielded $50 \%$ enzyme reactivation $\left(\mathrm{R}_{50}\right)$. Irinotecan $\left(\mathrm{CAMPTO}^{\circledR}\right)$ was purchased from Aventis Pharma Ltd. It was used in the form of irinotecan hydrochloride trihydrate. Before use, it was dissolved in $5 \mathrm{ml}$ of provided sterile solution to a final concentration of $20 \mathrm{mg} / \mathrm{ml}$. The concentrations of the antineoplastic drug tested in our in vitro experiment were $9.0 \mu \mathrm{g} / \mathrm{ml}$ and 4.6 $\mu \mathrm{g} / \mathrm{ml}$, corresponding, respectively, to doses of 350 $\mathrm{mg} / \mathrm{m}^{2}$, recommended in monotherapy, and $180 \mathrm{mg} /$ $\mathrm{m}^{2}$ recommended in combination chemotherapy in adult patients. Other chemicals and reagents used, if not specified, were purchased form Sigma Chemical Co. (St. Louis, MO, USA).

Inhibition of AChE by HI-6 and irinotecan. a) The concentration of the compound yielding a $50 \%$ enzyme inhibition $\left(\mathrm{IC}_{50}\right)$ was determined by incubating erythrocytes with four or more different concentrations of both compounds at $37^{\circ} \mathrm{C}$ and assaying for AChE activity after $15 \mathrm{~min}$. The changes in the enzyme activity are presented as the percent- age of activity of the respective of control. Only values between $10 \%$ and $90 \%$ inhibition were used for calculation. b) For the purpose of biochemical experiments, we also determined the catalytic activity of AChE previously inhibited with two different concentrations of irinotecan $(9.0$ and $4.6 \mu \mathrm{g} / \mathrm{ml})$ or HI-6 $\left(37.7 \mu \mathrm{g} / \mathrm{ml} ; 1 / 4\right.$ of its $\left.\mathrm{IC}_{50}\right)$. The reaction mixture was incubated for 10, 30, 60, 120, 150 and $180 \mathrm{~min}$ at $37^{\circ} \mathrm{C}$ after addition of each drug and the activity of AChE was measured. Each sample was assayed in triplicate, and a mean value was then calculated. The effects of irinotecan and HI-6 were expressed as percentages of the AChE activity of the respective of control.

Protective potency of HI-6. The protective potency of HI-6 with respect to irinotecan-inhibited AChE was tested by measurement of enzyme inhibition in the presence and absence of HI-6. Native human erythrocytes were diluted with phosphate buffer, $\mathrm{pH}$ 7.4; HI-6 $(37.7 \mu \mathrm{g} / \mathrm{ml})$ and irinotecan (4.6 and $9.0 \mu \mathrm{g} / \mathrm{ml}$ ) were added in succession. Irinotecan was added 1,5 or 15 min after HI-6, the reaction mixture was then incubated at $37^{\circ} \mathrm{C}$ for further $30 \mathrm{~min}$ and activity of AChE was measured. The in vitro protective efficiency of HI-6 against irinotecan inhibition of human erythrocyte AChE was expressed as protective potency $(\mathrm{Pp})$.

Reactivating potency of HI-6. Native human erythrocytes were incubated with two different concentrations of irinotecan $(4.6$ or $9.0 \mu \mathrm{g} / \mathrm{ml}$ ) for $15 \mathrm{~min}$ at $4^{\circ} \mathrm{C}$ to obtain approx. $90-95 \%$ inhibition of $\mathrm{AChE}$ activity. The reaction mixture was diluted (1:600) with phosphate buffer and the activity of AChE was measured in the presence of irinotecan and HI-6 $(37.7 \mu \mathrm{g} / \mathrm{ml})$. Simultaneously, the activity of AChE from native erythrocytes diluted identically was measured in the presence of HI-6. Prior to AChE assay, the reaction mixture was incubated at $37^{\circ} \mathrm{C}$ for $0.5,1$ or $24 \mathrm{~h}$. The percentage of reactivation (\%R) was calculated according to De Jong et al. (1989).

Assessment of cyto/genotoxicity of HI-6. Experimental design: Two independent experiments were conducted on the same blood sample and the data were pooled. Aliquots of whole blood ( $\mathrm{V}=0.5$ $\mathrm{ml}$ ) were placed in sterile plastic tubes containing RPMI culture medium (Gibco; V = $6 \mathrm{ml}$ ) without serum or mitotic activator. Duplicate cultures per sample were set up, treated with HI-6 and were incubated for $30 \mathrm{~min}$ at $37 \pm 1^{\circ} \mathrm{C}$ in humified atmosphere with $5.0 \% \mathrm{CO}_{2}$ (Heraeus Hera Cell 240 incubator). The final concentrations of HI-6 in culture medium with human blood cells in this in vitro experiment were $2.5 \times 10^{-1} \mathrm{mM}\left(1 / 4 \mathrm{LD}_{50}\right) ; 4.2 \times 10^{-1} \mathrm{mM}\left(\mathrm{IC}_{50}\right)$; $2.2 \times 10^{-1} \mathrm{mM}\left(\mathrm{P}_{50}\right)$ and $2.0 \times 10^{-2} \mathrm{mM}\left(\mathrm{R}_{50}\right)$. Negative and positive controls were also included and handled in the same manner. Following treatment, cultures were centrifuged for $10 \mathrm{~min}$ at 600 r.p.m., 
and the culture medium containing HI-6 was carefully removed. A part of the treated samples was immediately used for the preparation of slides for the alkaline comet assay and DNA diffusion assay. Other blood samples were used for the analysis of structural chromosome aberrations and cytochalasinblocked micronucleus assay (CBMN assay). These blood cells after centrifugation were washed twice in fresh RPMI medium and cultivated for further 48 $\mathrm{h}$ in vitro according to the standard procedure.

The alkaline comet assay. The comet assay was carried out under alkaline conditions, basically as described by Singh et al. (1991). Fully frosted slides were covered with $1 \%$ normal melting point (NMP) agarose. After solidification, the gel was scraped off from the slide. The slides were then coated with $0.6 \%$ NMP agarose. When this layer had solidified a second layer containing the blood sample $(5 \mu \mathrm{l})$ mixed with $0.5 \%$ low melting point (LMP) agarose was placed on the slides. After $10 \mathrm{~min}$ of solidification on ice, slides were covered with $0.5 \%$ LMP agarose. Afterwards the slides were immersed for $1 \mathrm{~h}$ in ice-cold freshly prepared lysis solution $(2.5 \mathrm{M}$ $\mathrm{NaCl}, 100 \mathrm{mM} \mathrm{Na}{ }_{2}$ EDTA, $10 \mathrm{mM}$ Tris/HCl, 1\% Nasarcosinate, $\mathrm{pH} 10$ ) with $1 \%$ Triton $\mathrm{X}-100$ and $10 \%$ dimethyl sulfoxide added fresh to lyse cells and allow DNA unfolding. The slides were then randomly placed side by side in a horizontal gel-electrophoresis tank, facing the anode. The unit was filled with freshly prepared electrophoretic buffer $(300 \mathrm{mM}$ $\mathrm{NaOH}, 1 \mathrm{mM} \mathrm{Na} \mathrm{E}_{2} \mathrm{EDTA}, \mathrm{pH}$ 13.0) and the slides were left in this alkaline buffer for $20 \mathrm{~min}$ to allow DNA unwinding and expression of alkali-labile sites. Denaturation and electrophoresis were performed at $4^{\circ} \mathrm{C}$ under dim light. Electrophoresis was carried out for the next $20 \mathrm{~min}$ at $25 \mathrm{~V}(300 \mathrm{~mA})$. After electrophoresis the slides were washed gently three times at 5-min intervals with a neutralisation buffer $(0.4 \mathrm{M}$ Tris/HCl, $\mathrm{pH}$ 7.5) to remove excess alkali and detergents. Each slide was stained with ethidium bromide $(20 \mu \mathrm{g} / \mathrm{ml})$ and covered with a coverslip. Slides were stored at $4^{\circ} \mathrm{C}$ in humidified sealed containers until analysis. To prevent additional DNA damage, handling of blood samples and all steps in the preparation of slides for the comet analysis were conducted under yellow light or in the dark. Furthermore, to avoid possible position effects during electrophoresis two parallel replicate slides per sample were prepared. Each replicate was processed in a different electrophoretic run. Corresponding negative and positive controls were also included. As a positive control hydrogen peroxide treatment $(1 \mathrm{mM} ; 5 \mathrm{~min}$ exposure on ice) was used.

Slides were examined at 250× magnification using a fluorescence microscope (Zeiss, Germany), equipped with an excitation filter of 515-560 nm and a barrier filter of $590 \mathrm{~nm}$. The microscope was con- nected through a black and white camera to a computer-based image analysis system (Comet Assay II, Perceptive Instruments Ltd, UK). A total of 100 comets per sample were scored (50 from each of two replicate slides). Comets were randomly captured at a constant depth of the gel, avoiding the edges of the gel, occasional dead cells and superimposed comets. To avoid the potential variability, one welltrained scorer performed all scoring of the comets. Three comet parameters: tail length, tail DNA percentage and tail moment were evaluated. Statistical analyses were carried out using Statistica 5.0 software (StatSoft, Tulsa, USA). Each sample was characterized for the extent of DNA damage by considering the mean ( \pm standard error of the mean), median and range for the comet tail lengths measured. In order to normalize the distribution and to equalize variances, a logarithmic transformation of data was applied. Multiple comparisons between groups were done by means of ANOVA on log-transformed data. Post-hoc analysis of differences was done by Scheffé test. The level of statistical significance was set at $P<0.05$.

DNA diffusion assay. Twelve hours after the end of each treatment, DNA diffusion assay was performed. We followed the protocol described by Singh (2003). Chemicals needed for DNA diffusion assay were provided by Sigma. Agarose-precoated slides were made by spreading $50 \mathrm{ml}$ of $0.7 \%$ normal melting agarose on each slide and drying them at room temp. Microgels were made on the agarose-precoated slides by mixing $25 \mu \mathrm{l}$ of whole blood culture (10000 lymphocytes) with $50 \mu \mathrm{l}$ of $0.8 \%$ high-resolution agarose and pipetting it onto the slide. The gel was immediately covered with a cover glass. The slides were coded and cooled on ice for $1 \mathrm{~min}$. The cover glasses were removed, and $200 \mu \mathrm{l}$ of $2 \%$ agarose solution was layered and again covered with the cover glass. After keeping slides for $1 \mathrm{~min}$ on ice, cover glasses were removed and the slides were immersed in a freshly made lysing solution $(1.25 \mathrm{M} \mathrm{NaCl}, 1 \mathrm{mM}$ EDTA, $5 \mathrm{mM}$ Tris/ $\mathrm{HCl} \mathrm{pH} 10,0.01 \%$ sodium lauroyl sarcosine, $0.2 \%$ DMSO added freshly, $300 \mathrm{mM} \mathrm{NaOH}$ added freshly) for $10 \mathrm{~min}$ at room temperature. After lysis, the slides were immersed in neutralizing solution (50\% ethanol, $1 \mathrm{mg} / \mathrm{ml}$ spermine, $20 \mathrm{mM}$ Tris $/ \mathrm{HCl}$ $\mathrm{pH}$ 7.4) for $30 \mathrm{~min}$ at room temp., twice. The slides were air-dried and stored at room temp. Slides were stained with YOYO- 1 dye $(0.25 \mu \mathrm{M}$ YOYO1 in $2.5 \%$ DMSO, $0.5 \%$ sucrose) for $15 \mathrm{~min}$. Onethousand lymphocytes per slide were analyzed. Lymphocytes undergoing apoptosis or necrosis were distinguished from normal cells according to figures and instructions given by Singh (2003). Apoptotic cell nuclei have a hazy or undefined outline without any clear boundary due to nucleosomal- 
sized DNA diffusing into agarose. Necrotic cell nuclei are bigger and are poorly defined. They have a clear, defined outer boundary of the DNA halo and a relatively homogeneous appearance of the halo. In the contrast, cell nuclei with only damaged DNA (not necrotic or apoptotic) are clearly defined and their nuclei have a larger halo with a clear outer boundary.

Chromosome aberration (CA) test. The chromosome aberration test was performed according to current IAEA guidelines (2001) with some modifications. Blood samples were cultivated in RPMI-1640 medium (Gibco) containing inorganic salts, all amino acids, vitamins and other components. The medium was supplemented with $20 \%$ fetal calf serum (Gibco), 10\% autologous serum, penicillin (100 IU/ml; Sigma), and streptomycin $(100 \mu \mathrm{g} / \mathrm{ml}$; Sigma). For mitotic stimulation phytohaemagglutinin (Apogent) was added. Duplicate cultures per sample were set up and incubated at $37 \pm 0.5^{\circ} \mathrm{C}$ for $48 \mathrm{~h}$ in humified atmosphere with $5.0 \% \mathrm{CO}_{2}$. Corresponding negative and positive controls (ethyl methanesulfonate, $30 \mu \mathrm{g} /$ $\mathrm{ml}$ ) were also included. Preparations were made according to standard procedure. Slides were stained with 5\% Giemsa solution (Sigma). All slides were coded and scored blindly. Five-hundred metaphases per sample were analysed for chromosomal aberrations. Structural chromosome aberrations were classified based on the number of sister chromatids and breakage events involved. Only metaphases containing 45-47 centromeres were analysed. Percentages and types of aberrations per each sample were determined. Statistical significance of the results obtained was evaluated by $\chi^{2}$ test. The level of statistical significance was set at $P<0.01$.

Cytochalasin-blocked micronucleus assay (CBMN). Lymphocyte cultures were incubated according to a standard protocol for CBMN assay (Fenech \& Morley, 1985). Corresponding negative and positive controls (bleomycin, $10 \mu \mathrm{g} / \mathrm{ml}$ ) were also included. Cytochalasin B at a final concentration of $6 \mu \mathrm{g} / \mathrm{ml}$ was added to the culture at $44 \mathrm{~h}$. For MN identification the criteria of Fenech et al. (2003) were used. The number of micronuclei (MN) in 2000 binucleated (BN) cells was scored for each treatment and the number of $\mathrm{BN}$ cells with $\mathrm{MN}$ was also recorded. On the same slides the proliferation index was also evaluated by classifying cells according to the number of nuclei (cytokinesis-block proliferation index, CBPI), as suggested by Surralles and co-workers (1995) until 1000 binuclear lymphocytes were scored. We used their formula: $\mathrm{CBPI}=[\mathrm{M} 1+2 \mathrm{M} 2+3(\mathrm{M} 3+\mathrm{M} 4)] / \mathrm{N}$ where $\mathrm{M} 1-\mathrm{M} 4$ indicate the number of cells with 1-4 nuclei, respectively, and $\mathrm{N}$ the total number of cells scored.

\section{RESULTS}

\section{Inhibition of AChE by HI-6 and irinotecan}

To further address the question of whether irinotecan acts as specific AChE blocker, we checked its action in vitro on human erythrocyte AChE. Results obtained in previous in vitro studies suggest that this drug interacts directly with various molecular forms of $\mathrm{AChE}$, leading to a non-competitive inhibition of this enzyme (Morton et al., 1999; Dodds \& Rivory, 1999). In our experiments, the inhibitory power $\left(\mathrm{IC}_{50}\right)$ of irinotecan on $\mathrm{AChE}$ of human erythrocytes was determined and compared with the HI-6 oxime a known reversible inhibitor of AChE and antidotal drug in organophosphorus poisoning. The $\mathrm{IC}_{50}$ values obtained were $5.0 \times 10^{-4} \mathrm{mmol} / \mathrm{l}$ for irinotecan and $4.2 \times 10^{-1} \mathrm{mmol} / \mathrm{l}$ for HI- 6 (Fig. 2). The values indicate that HI- 6 is an approx. 840 -fold less potent inhibitor than irinotecan, which was found to be a strong inhibitor of ACh hydrolysis by AChE. Also, a decrease of the catalytic activity of a human erythrocyte AChE with prolonged incubation of cells with either dose of irinotecan. There was a slight reduction in the inhibition of AChE by both of doses of irinotecan with increased incubation times. The higher dose of irinotecan inhibited the AChE activity with a potency similar to that estimated for physostigmine in our previous study (Kopjar et al., 2007). HI- 6 inhibited the AChE activity by up to 50\% 150 min after its addition (Fig. 3).

\section{Protective potency}

The protective potency of HI-6 towards human erythrocyte AChE inhibited by two different doses of irinotecan is given in Table 1 . The residual activities after inhibition with irinotecan (4.6 and 9.0 $\mu \mathrm{g} / \mathrm{ml}$ ) were 6.7 and $6.0 \%$, respectively. HI-6 demonstrated a good protective potency against inhibition

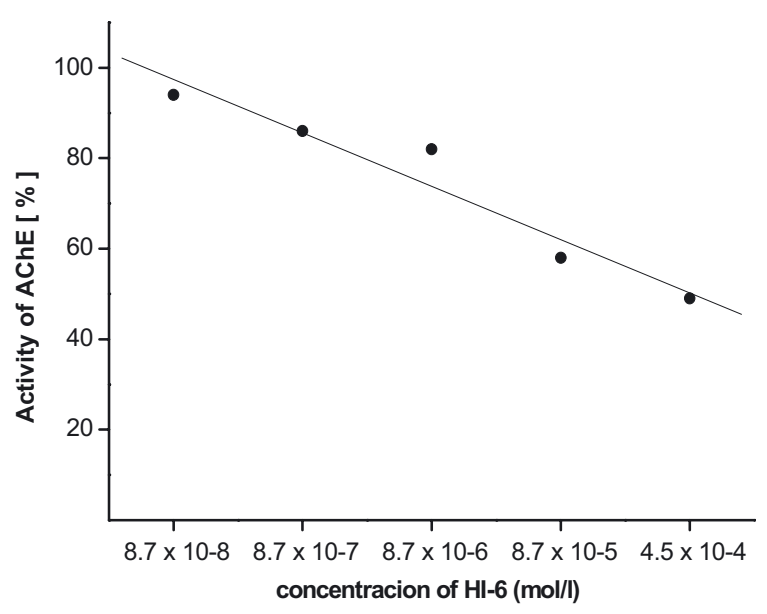

Figure 2. In vitro inhibition of AChE by HI-6. 


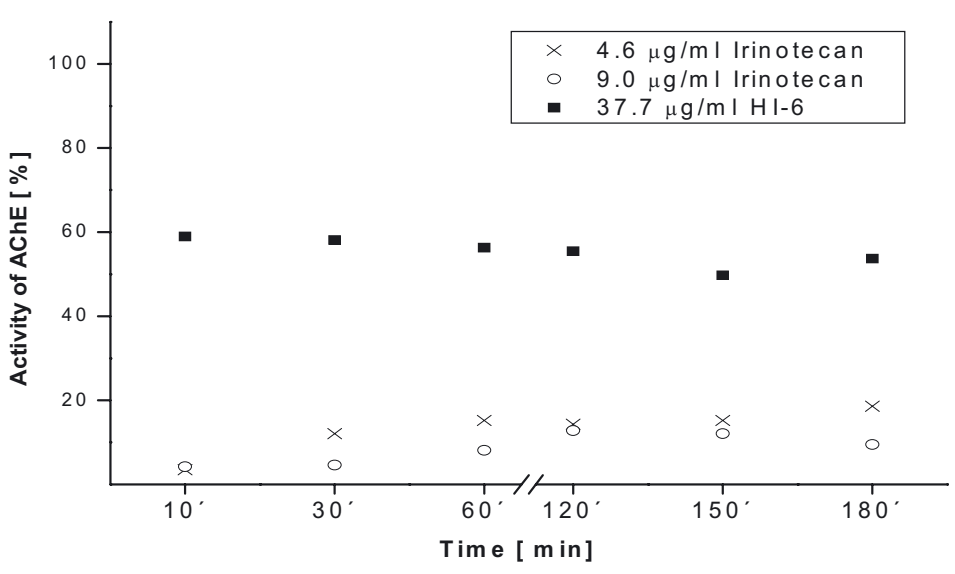

Figure 3. Progressive inhibition of AChE by HI-6 and irinotecan. of AChE with both concentrations of irinotecan. The AChE activity in the presence of HI- 6 was increased up to $30 \%$ of the irinotecan-inhibited level. The best result was obtained when the oxime was used $5 \mathrm{~min}$ before irinotecan $(4.6 \mu \mathrm{g} / \mathrm{ml})$. Also, under same experimental conditions a higher dose of irinotecan did not induce an expected decrease in AChE activity that was decreased only by $8-10 \%$. We obtained identical or similar results when irinotecan was added 1 or 15 min after HI-6. All in all, these results indicated that HI-6 is able to protect AChE against inhibition by irinotecan.

\section{Reactivating potency}

The ability of HI-6 (applied at a final concentration of $1 / 4$ of its $\mathrm{IC}_{50}$ value) to reactivate irinotecan-inhibited human erythrocyte AChE is shown in Table 1, too. Reactivation was quantitated using the De Jong's equation for the calculation of percentage of reactivation. The range of reactivation was from 36 to $50 \%$. The highest percentage of AChE activity $(50 \%)$ previously inhibited by irinotecan $(4.6 \mu \mathrm{g} / \mathrm{ml})$ was obtained $24 \mathrm{~h}$ after addition of HI-6. According to the obtained results, the HI-6 oxime seems to be a potent $\mathrm{AChE}$ reactivator at the concentration of $1 / 4$ of its $\mathrm{IC}_{50}$. This concentration level could be relevant for human use (Tattersall, 1993).

\section{The alkaline comet assay}

Results of the alkaline comet assay indicate that the exposure of human blood to HI-6 in concentrations tested did not induce any significant increase of primary DNA damage in white blood cells as compared to negative control. On the other hand, the values of all comet parameters (tail length, tail DNA percentage and tail moment) recorded in the positive control were significantly increased $(P<0.01$, ANOVA with post-hoc Schéffe test) as compared both to HI-6-treated samples and untreated cells (Table 2). This is also clearly visible in Fig. 4, where the results of the evaluation of DNA damage in individual samples are displayed in the form of Box and Whisker diagrams.

\section{DNA diffusion assay}

Results of the DNA diffusion assay indicate that the exposure of human blood to HI-6 in concentrations tested induced only a slight, non-significant increase in the percentage of apoptotic cells as compared to negative control. On the other hand, the percentage of apoptotic cells observed in the positive control were significantly higher $(P<0.01$, $\chi^{2}$ test) as compared both to HI-6-treated samples and untreated cells. Necrotic cells were observed only in blood sample treated with HI-6 in concentration corresponding to $\mathrm{R}_{50}$ (but this was not statistically significant) as well as in the positive control (Table 2).

\section{Analysis of structural chromosome aberrations in lymphocytes}

In vitro treatment with HI-6 did not induce a significant increase of chromosomal damage in peripheral blood lymphocytes as compared to negative control. It mainly induced one to four additional chromatid breaks, while a single acentric fragment was recorded only in the sample treated with the concentration corresponding to $\mathrm{IC}_{50}$. On the other

Table 1. In vitro biological efficiency a of HI-6 on AChE inhibited by irinotecan

\begin{tabular}{lllllll}
\hline \multirow{2}{*}{$\begin{array}{l}\text { Concentration } \\
\text { of irinotecan }\end{array}$} & \multicolumn{2}{l}{ Pp $(\%)$} & \multicolumn{4}{l}{$\mathrm{R}(\%)$} \\
\cline { 2 - 7 }$(\mu \mathrm{g} / \mathrm{ml})$ & 1 & 5 & 15 & 0.5 & 6 & 24 \\
\hline 4.6 & 28 & 30 & 25 & 40 & 36 & 50 \\
9.0 & 20 & 20 & 17 & 25 & 25 & 40 \\
\hline
\end{tabular}

aPp is the protective potency of HI- 6 expressed as percentage of preserved activity of $\mathrm{AChE}$ in the presence of two concentrations of irinotecan; $\mathrm{R}$ is percentage of reactivation of human erythrocyte AChE with HI-6, previously inhibited by irinotecan. 
Table 2. Results of alkaline comet assay and DNA diffusion assay on human white blood cells treated in vitro with HI-6.

\begin{tabular}{|c|c|c|c|c|c|c|c|c|c|c|c|}
\hline \multirow{3}{*}{ Sample } & \multicolumn{9}{|c|}{ Alkaline comet assay } & \multicolumn{2}{|c|}{ DNA diffusion assay } \\
\hline & \multicolumn{3}{|c|}{ Tail length $(\mu \mathrm{m})$} & \multicolumn{3}{|c|}{ Tail intensity (DNA \%) } & \multicolumn{3}{|c|}{ Tail moment } & \multirow{2}{*}{$\begin{array}{l}\text { Apoptosis } \\
\%\end{array}$} & \multirow{2}{*}{$\frac{\text { Necrosis }}{\%}$} \\
\hline & Mean \pm SE & Min & Max & Mean \pm SE & Min & Max & Mean \pm SE & Min & Max & & \\
\hline $\begin{array}{l}\mathrm{HI}-6^{1 / 4} \\
\mathrm{LD}_{50}\end{array}$ & $13.61 \pm 0.13$ & 11.54 & 16.67 & $0.74 \pm 0.07$ & 0.00 & 2.81 & $0.09 \pm 0.01$ & 0.00 & 0.36 & 0.51 & 0.00 \\
\hline $\begin{array}{l}\mathrm{HI}-6 \\
\mathrm{IC}_{50}\end{array}$ & $12.87 \pm 0.13$ & 10.26 & 16.03 & $0.66 \pm 0.14$ & 0.00 & 10.38 & $0.08 \pm 0.02$ & 0.00 & 1.20 & 0.58 & 0.00 \\
\hline HI-6 $\mathrm{P}_{50}$ & $13.08 \pm 0.12$ & 10.26 & 18.59 & $0.74 \pm 0.19$ & 0.00 & 13.28 & $0.09 \pm 0.03$ & 0.00 & 1.87 & 0.78 & 0.00 \\
\hline HI-6 $\mathrm{R}_{50}$ & $13.27 \pm 0.16$ & 10.26 & 23.08 & $0.30 \pm 0.07$ & 0.00 & 5.00 & $0.04 \pm 0.01$ & 0.00 & 0.64 & 0.78 & 0.17 \\
\hline $\begin{array}{l}\text { Positive } \\
\text { control }\end{array}$ & $18.62 \pm 0.84^{*}$ & 10.26 & 68.59 & $1.98 \pm 0.42^{*}$ & 0.00 & 24.88 & $0.38 \pm 0.10^{*}$ & 0.00 & 6.54 & $26.04^{*}$ & 0.24 \\
\hline $\begin{array}{l}\text { Negative } \\
\text { control }\end{array}$ & $13.24 \pm 0.10$ & 10.26 & 16.03 & $0.29 \pm 0.05$ & 0.00 & 1.91 & $0.04 \pm 0.01$ & 0.00 & 0.25 & 0.40 & 0.00 \\
\hline
\end{tabular}

aTreatments lasted for for $30 \mathrm{~min}$. Negative control and positive control (1 mM hydrogen peroxide) were also included. Primary DNA damage was evaluated in 100 comets per sample and statistical evaluation (ANOVA with post-hoc Schéffe test) was done on logarithmically transformed data. For DNA diffusion assay 1000 cells per slide were analyzed and statistical evaluation was performed by $\chi^{2}$ test. ${ }^{*} P<0.01$ as compared to all other samples.

hand, ethyl methanesulfonate (positive control) caused a clear positive response both in the frequency and types of chromosomal aberrations recorded (Table 3).

\section{Cytokinesis-block micronucleus (CBMN) assay}

The induction of micronucleated lymphocytes by HI-6 is shown in Table 4 . Even at the highest

Table 3. Structural chromosome aberrations in human peripheral blood lymphocytes treated ${ }^{\mathrm{a}}$ with HI-6 in vitro.

\begin{tabular}{lllllll}
\hline \multirow{2}{*}{ Sample } & \multirow{2}{*}{$\begin{array}{l}\text { Cells with CA } \\
(\%)\end{array}$} & \multicolumn{5}{l}{ No. of structural chromosome aberrations/500 cells } \\
\cline { 3 - 7 } & & $\Sigma$ & $\begin{array}{l}\text { Chromatid } \\
\text { break }\end{array}$ & $\begin{array}{l}\text { Chromosome } \\
\text { break }\end{array}$ & $\begin{array}{l}\text { Quadriradial } \\
\text { figure }\end{array}$ & $\begin{array}{l}\text { Acentric } \\
\text { fragment }\end{array}$ \\
\hline HI-6 1/4 LD & 0.8 & 4 & 4 & - & - & - \\
HI-6 IC & & 2 & 1 & - & - & 1 \\
HI-6 P & 0.4 & 3 & 3 & - & - & - \\
HI-6 R & 0.6 & 2 & 2 & - & 1 & - \\
Positive control & $4.4^{*}$ & $25^{*}$ & $19^{*}$ & 1 & - & $4^{*}$ \\
Negative control & 0.4 & 2 & 2 & - & - \\
\hline
\end{tabular}

aTreatments lasted for $30 \mathrm{~min}$. Negative control and positive control (ethyl methanesulfonate, $30 \mu \mathrm{g} / \mathrm{ml}$ ) were also included Statistic evaluation was done using $\chi^{2}$ test; ${ }^{*} P<0.01$ as compared to all other samples.

Table 4. Results of CBMN assay in human peripheral blood lymphocytes treated ${ }^{a}$ in vitro HI-6.

\begin{tabular}{|c|c|c|c|c|c|c|c|c|c|c|c|c|c|c|}
\hline \multirow{2}{*}{ Sample } & \multirow{2}{*}{$\begin{array}{l}\Sigma \\
\text { MNed } \\
\text { BN }\end{array}$} & \multicolumn{3}{|c|}{ No. of BN with } & \multirow{2}{*}{$\begin{array}{l}\Sigma \\
\mathrm{MN}\end{array}$} & \multicolumn{4}{|c|}{ Total No. of } & \multicolumn{5}{|c|}{ Lymphocyte proliferation } \\
\hline & & $1 \mathrm{MN}$ & $2 \mathrm{MN}$ & $3 \mathrm{MN}$ & & NB & NPB & $\mathrm{APO}$ & $\mathrm{NC}$ & M1 & M2 & M3 & M4 & CBPI \\
\hline HI-6 $1 / 4 \mathrm{LD}_{50}$ & 13 & 13 & - & - & 13 & 6 & 1 & 4 & - & 826 & 1000 & 19 & 44 & 1.60 \\
\hline HI-6 $\mathrm{IC}_{50}$ & 16 & 15 & 1 & - & 17 & 5 & 1 & 2 & - & 1337 & 1000 & 18 & 49 & $1.47^{\#}$ \\
\hline HI-6 $\mathrm{P}_{50}$ & 12 & 10 & 2 & - & 14 & 5 & - & 2 & - & 910 & 1000 & 23 & 117 & 1.62 \\
\hline HI-6 $\mathrm{R}_{50}$ & 12 & 10 & 2 & - & 15 & 5 & 1 & 1 & - & 927 & 1000 & 17 & 122 & 1.62 \\
\hline $\begin{array}{l}\text { Positive } \\
\text { control }\end{array}$ & 60 & 45 & 12 & 3 & $78^{*}$ & $18^{*}$ & 3 & $15^{*}$ & $8^{*}$ & 851 & 1000 & 16 & 20 & 1.57 \\
\hline $\begin{array}{l}\text { Negative } \\
\text { control }\end{array}$ & 13 & 12 & 1 & & 14 & 3 & - & 2 & - & 809 & 1000 & 28 & 17 & 1.59 \\
\hline
\end{tabular}

aTreatments lasted for $30 \mathrm{~min}$. Negative control and positive control (bleomycin, $10 \mu \mathrm{g} / \mathrm{ml}$ ) were also included. Binucleate cells, 2000, (i.e. 4000 nuclei) were scored to determinate total number of micronuclei $(\mathrm{MN})$ for each experimental point. MNed, micronucleated; $\mathrm{BN}$, binuclear cells; NB, nuclear buds; NPB, nucleoplasmic bridges; APO, apoptosis; NC, necrosis; CBPI, cytokinesis-block proliferation index is computed by the formula CBPI $=[\mathrm{M} 1+2 \mathrm{M} 2+3(\mathrm{M} 3+\mathrm{M} 4)] / \mathrm{N}$ where M1-M4 indicate the number of cells with $1-4$ nuclei, respectively, and $\mathrm{N}$ the total number of cells scored. Statistic evaluation was done using $\chi^{2}$ test; ${ }^{*}$ significantly different $(P<0.05)$ as compared with all other samples; \#significantly different $(P<0.05)$ as compared with all samples except positive control. 
concentration of the oxime tested, the MN frequency was not significantly different compared to negative control. On the other hand, bleomycin (used as a positive control) increased the number of micronuclei over 4-fold. The majority of BN in HI-6-treated samples contained only one $\mathrm{MN}$ with only a small proportion with $2 \mathrm{MN}$, while $\mathrm{BN}$ with $3 \mathrm{MN}$ were recorded only in the positive control (Table 4). Besides the induction of $\mathrm{MN}$, in vitro treatment with HI-6 also induced formation of nuclear buds, nucleoplasmic bridges and apoptotic cells, but their frequencies were not significantly higher than in the negative control. In HI-6-treated samples and negative control no necrotic cells were observed, while
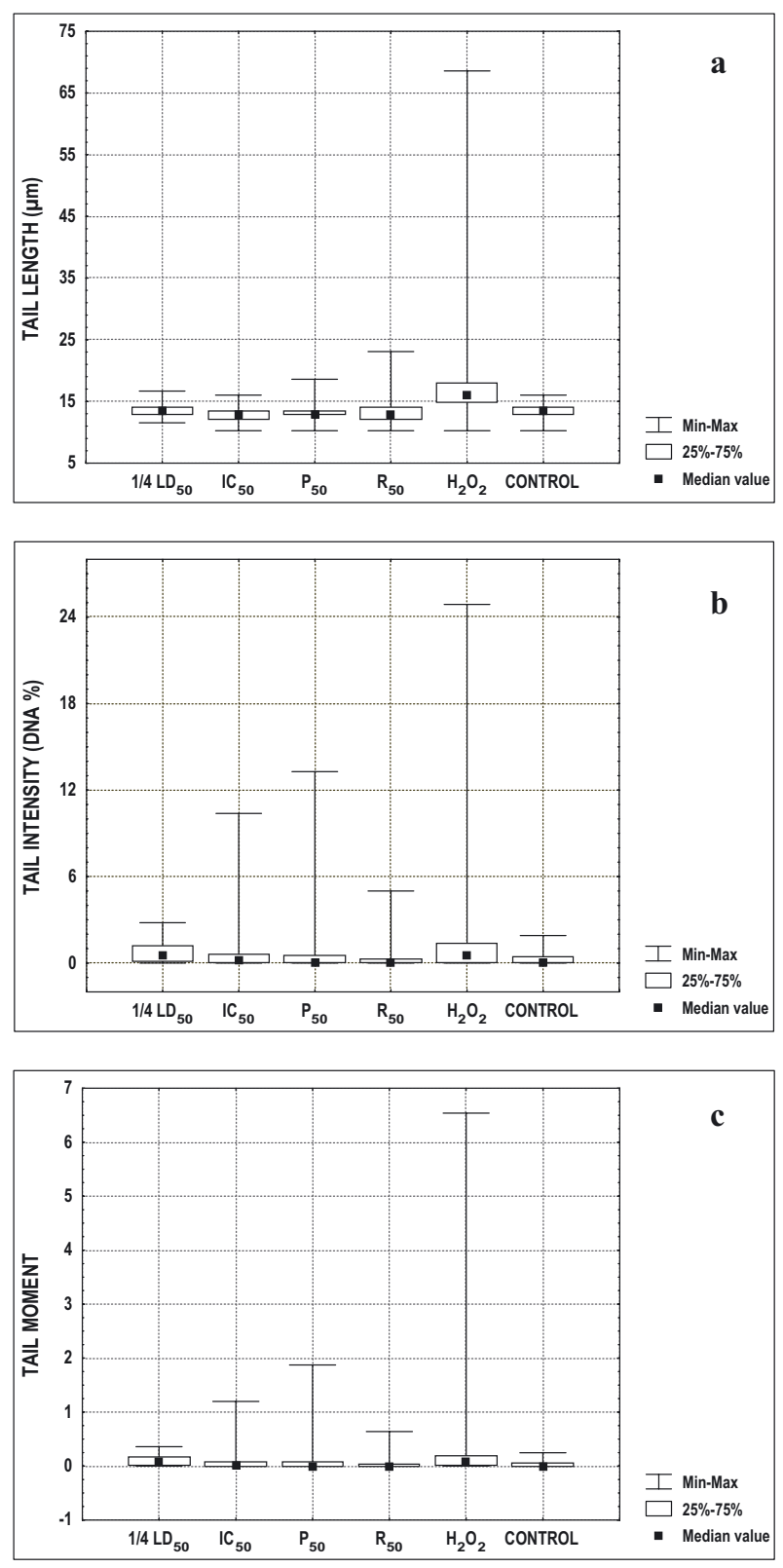

Figure 4. Distribution of comet parameters measured in HI-6-treated leukocytes. their frequency in the positive control was 8 necrotic cells per 2000 binuclear cells (Table 4). The values of cytokinesis-block proliferation index indicate that HI-6 retarded lympohcyte proliferation in vitro only at the concentration corresponding to $\mathrm{IC}_{50}$ (Table 4).

\section{DISCUSSION}

The treatment of cancer disease by chemotherapy is presently common. Chemotherapy may be used either alone or in conjunction with surgical removal of a tumour and/or radiation therapy. Although the goal of chemotherapy is to eliminate cancer cells while sparing the normal ones, some adverse effects in normal cells are almost always observed. The two major obstacles in an effective cancer therapy are drug resistance and toxicity to normal organs that prevent the use of optimal doses and schedules. The development of non-toxic selective and effective cytoprotective compounds that preferentially protect normal tissues from chemotherapy toxicity, without protecting the malignant tissue, is a major challenge in cancer chemotherapy research. Such compounds could potentially protect against the genetic damage, mutation, immune system alterations, as well as teratogenic effects.

The most susceptible cells during chemotherapy are those with a high rate of cell division, e.g., bone marrow, hair bulb and the gastrointestinal tract. Besides, the nervous system is frequently a site of symptomatic toxicity of antineoplastic agents. Chemotherapy induces stress in the nervous system (both central and peripheral) by inhibiting its ability to efficiently transmit nerve impulses along the synapse. Neurotoxicity, as a common unwanted side-effect of antineoplastic drugs, can cause significant long-standing disability because regeneration of the nervous system is poor. For example, it has been found that administration of high levels of the therapeutic agent taxol may result in severe neurotoxicity in the form of peripheral neuropathy (US Patent 5916903). Furthermore, most of the chemotherapy regimens currently used for treatment of the colorectal carcinoma are neurotoxic. It is also well documented that oxaliplatin, the newest drug used in treatment of colorectal carcinoma, induces peripheral neuropathy (Goetz et al., 2003). However, it is the only treatment modality for patients who cannot be treated with irinotecan due to a preexisting liver disfunction or other reasons. Irinotecan, on the other hand, is a potent AChE inhibitor, which activity is likely responsible, at least in part, for the cholinergic syndrome that is observed following its intravenous infusion (Tobin et al., 2004; Hyatt et al., 2005).

Until today the cholinergic syndrome induced with irinotecan has been treated mainly with atro- 
pine (ACh receptor antagonist), which reduces or alleviates the effects of antineoplastic disease treatment. Unfortunately, after its administration, a toxic reaction to atropine resulting from its anti-cholinergic action and including a variety of peripheral and central manifestations cannot be excluded. This toxic effect may occur at the usual therapeutic doses (Economacos \& Kanakis, 1981).

AChE reactivators (oxime), such as HI-6, have been used in conjunction with the muscarinic cholinergic receptor antagonist atropine to provide in vivo protection against nerve agents and other organophosphorus compounds (Somani \& Romano, 2001). However, AChE reactivators have not been previously employed to alleviate the side effects of antineoplastic disease treatment (US Patent 5916903). In this in vitro study an attempt was made to establish whether the HI-6 oxime, being known AChE reactivator, has a potency to enhance the activity of red blood cell AChE in human whole blood samples previously treated with irinotecan. All our initial results seem very promissing, although they cannot provide evidence for therapeutic effectiveness of HI-6 in clinical settings. Irinotecan and HI-6 showed different in vitro toxic effects on human erythrocyte $\mathrm{AChE}$, which corresponds well to the results of their toxicity previously obtained by other authors (Mesić et al., 1991; Dodds \& Rivory, 1999; Tobin et al., 2004). In contrast to irinotecan, HI-6 is a poor inhibitor of human erythrocyte $\mathrm{AChE}$ in vitro. The $\mathrm{IC}_{50}$ value of $\mathrm{HI}-6$ indicates low affinity of this compound for AChE, although it contains a quaternary pyridinium moiety in the molecule, which is known to have a certain affinity for human erythrocyte AChE (Bevandić et al., 1985; Galoši et al., 1988). The enzymatic activity decreased by up to $50 \%$ when the enzyme was exposed to irinotecan at the concentration of $5.0 \times 10^{-4}$ $\mathrm{mmol} / \mathrm{l}$, or to HI- 6 at $4.2 \times 10^{-1} \mathrm{mmol} / \mathrm{L}$. Continuous decrease of activity of AChE up to $180 \mathrm{~min}$ after addition of HI- 6 was by $40-50 \%$. Under the same experimental conditions the activity of AChE was inhibited by irinotecan in doses comparable to those recommended in mono- or combination therapy, by between 85 and 95\%, and correlates with the activity of the same enzyme after inhibition with the well-known AChE irreversible blocker physostigmine (Kopjar et al., 2007). In our experiments we also demonstrated that HI-6 had a protective effect and reduced the degree of inhibition of AChE by irinotecan at least two-fold. Its chemical structure (the pyridinium rings, the bridge between pyridinium rings and the nucleofilic activity of the oxime anion that is bound to the pyridinium ring) is known to be important for the protective potency and rate of the reactivation of inhibited AChE. The much better reactivation than protection potency obtained with a concentration of HI-6 relevant for humans corresponded to its antidotal efficacy in organophosphorus poisoning (Kassa et al., 1997). Usually, the reactivating efficacy of an oxime in vitro corresponds to its therapeutic efficacy in vivo. For this reason we hope that this in vitro study will contribute to the progress in delineating new research strategies in the treatment of the cholinergic syndrome in patients with tumors. It is known that HI-6 crosses the blood-brain barrier (Clement, 1982) and we expect that it might protect or reactivate irinotecan-inhibited AChE in vivo, in the peripheral as well as in the central compartments of the nervous system.

Based on the results of the first part of this study concerning human erythrocyte AChE activity and its interactions with HI-6 oxime and the antineoplastic drug irinotecan, the relevance of this enzyme as surrogate marker of neuronal AChE activity is confirmed. Moreover, the data obtained in vitro indicate the potential of irinotecan to induce toxicity in the central nervous system which needs to be taken into account in future studies.

The present study reports for the first time results concerning possible genotoxic and cytoprotective effects of HI-6. Although the spectrum of cytoprotective agents available is relatively broad, most of them are either toxic or lack selective cytoprotective activity. Thus, HI- 6 , a member of the oxime family is certainly one of the promissing candidates for further studies (US Patent 5916903). According to its exceptional properties, confirmed earlier in the treatment of organophosphate poisoning, it seems reasonable to investigate its potential use in protection of AChE inhibited by antineoplastic drugs. Since the drug is still experimental, extensive studies on its toxicity are necessary before it may be approved for the use in human subjects. Therefore, to elucidate the toxicity profile of HI-6, in the present study the cyto/genotoxicity of the compound to peripheral blood leukocytes was studied in vitro using a variety of biomarkers.

Many techniques for detecting DNA damage could be used to identify potentially genotoxic substances. During recent years the comet assay or single cell gel electrophoresis has been established as a sensitive method for detecting DNA damage (Møller et al., 2000; Singh, 2000; Tice, 2000, Faust et al., 2004). One of the successful modifications of the method is the DNA diffusion assay (Singh, 2003) also employed in the present study in parallel with conventional cytogenetic techniques: chromosome aberration analysis and cytokinesis-block micronucleus assay.

Despite cytoprotective effects observed in non-proliferating cells, a substance could harm actively proliferating cells. To check this assumption 
we used three techniques that substantially differ in the levels of the damage detection. Whereas the comet assay detects DNA damage in single cells and independently of cell proliferation, chromosome aberration analysis and the cytokinesis-block micronucleus assay are applicable to proliferating cells only. Combination of such methods is extremely important when studying the effects of compounds with potential use in human and animal medicine.

The present study confirmed that the alkaline comet assay is a useful complement to the standard cytogenetic analyses. The results obtained using the alkaline comet assay suggest that HI-6 did not induce significant DNA damage in human leukocytes. The results obtained using DNA diffusion assay also indicate a low cytotoxicity of HI-6 in concentrations tested. In vitro treatment with HI-6 did not induce a significant increase of chromosomal damage in peripheral blood lymphocytes (a few additional chromatid breaks only). Moreover, the frequency of MN even at the highest concentration of the oxime tested was not significantly increased. However, the values of cytokinesis-block proliferation index indicate that HI-6 retarded lymphocyte proliferation in vitro in the high concentration corresponding to $\mathrm{IC}_{50}$. Trying to explain this observation, we also tested a higher concentration of the compound (corresponding to $\mathrm{LD}_{50}$ ) and confirmed the same growth inhibitory effect. Since the effects of HI6 in our study were investigated in human peripheral blood lymphocytes, a cell type that is predominantly in a DNA presynthetic stage of the cell cycle (i.e. the $\mathrm{G}_{0}$ phase), additional analyses using other cell types and metabolic activation are necessary. Namely, dormant cells often differ in their response to the treatment and usually have a lower DNA repair capacity as compared to actively proliferating cells.

Based on the results of all experiments performed in the present study, we can conclude that HI-6 possesses acceptably low genotoxicity in vitro and therefore might be also useful as a potential cytoprotector. Nevertheless, its activity should be tested on other cell types to elucidate whether it is applicable for extensive use in vivo.

\section{Acknowledgements}

This study was supported by the Ministry of Science, Education and Sports of the Republic of Croatia (grant No. 022-0222148-2139 and No. 0220222148-2137).

We wish to thank Mrs. M. Kramarić for technical assistance.

\section{REFERENCES}

Abigerges D, Armand JP, Chabot GG, Da Costa L, Fadel E, Cote C, Herait P, Gandia D (1994) Irinotecan (CPT-
11) high-dose escalation using intensive high-dose loperamide to control diarrhea. J Natl Cancer Inst 86: 446-449.

Aguilera L, Martinez-Bourio R, Cid C, Arino JJ, Saez de Eguilaz L, Arizaga A (1988) Anaphylactic reaction after atropine. Anesthesiology 43: 955-957.

Bevandić Z, Deljac A, Maksimović M, Bošković B, Binenfeld Z (1985) Methylthio analogues of PAM-2, TMB-4 and obidoxime as antidotes in organophosphate poisonings. Acta Pharm Jugosl 35: 213-218.

Bugat R, Suc E, Rougier P, Becouarn Y, Naieff I, Ychou M, Culine S, Extra JM, Adenis A, Ganem G (1994) CPT-11 (irinotecan) as second-line therapy in advanced colorectal cancer (CRC): preliminary results of multicentric Phase II study. Proc Annu Meet Am Soc Clin Oncol 13: A586.

Clement JG (1982) HI-6: reactivation of central and peripheral acetylcholinesterase following inhibition by soman, sarin and tabun in vivo in the rat. Biochem Pharmacol 31: 1283-1287.

De Jong LPA, Verhagen MAA, Langeberg JP, Hagedorn I, Loffler M (1989) The bispyridinium-dioxime Hlo-7. A potent reactivator for acetylcholinesterase inhibited by stereoisomers of tabun and soman. Biochem Pharmacol 38: 633-640.

Dodds HM, Rivory LP (1999) The mechanism for the inhibition of acetylcholinesterases by irinotecan (CPT-11). Mol Pharmacol 56: 1346-1353.

Economacos G, Kanakis J (1981) A case of hypersensitivity to atropine. Anesth Analg Reanim 38: 748.

Ellman GL, Courtney KD, Andres VJ, Featherstone RM (1961) A new and rapid colorimetric determination of acetylcholinesterase activity. Biochem Pharmacol 7: 8895.

Faust F, Kassie F, Knasmüller S, Boedecker RH, Mann M, Mersch-Sundermann V (2004) The use of the alkaline comet assay with lymphocytes in human biomonitoring studies. Mutat Res 566: 209-229.

Fenech M, Morley AA (1985) Measurement of micronuclei in lymphocytes. Mutat Res 147: 29-36.

Fenech M, Chang WP, Kirsch-Volders M, Holland N, Bonassi S, Zeiger E (2003) HUMN project: detailed description of the scoring criteria for the cytokinesis-block micronucleus assay using isolated human lymphocyte cultures. Mutat Res 534: 65-75.

Furman WL, Crews K, Daw NC, Rodriguez-Galindo C, Stewart C, Houghton PJ, Santana VM (2003) Cefixime (CFX) enables further dose-escalation of oral irinotecan (IRN) in pediatric patients with refractory solid tumors. Proc Annu Meet Am Soc Clin Oncol 22: 799.

Galoši A, Deljac A, Deljac V, Binenfeld Z (1988) Reactivators of acetylcholinesterase inhibited by organophosphorus compounds. Imidazole derivatives. Acta Pharm Jugosl 38: 23-29.

Gandia D, Abigerges D, Armand JP, Chabot G, da Costa L, De Forni M, Mathieu-Boue A, Herait P (1993) CPT11-induced cholinergic effects in cancer patients (letter). J Clin Oncol 11: 196-197.

Goetz MP, Erlichman C, Windebank AJ, Reid JM, Sloan JA, Artherton P, Adjei AA, Rubin J, Pitot H, Galanis E, Ames MM, Goldberg RM (2003) Phase I and Pharmacokinetic Study of two different schedules of oxaliplatin, irinotecan, fluorouracil, and leucovorin in patients with solid tumors. J Clin Oncol 21: 3761-3769.

Grisaru D, Sternfeld M, Eldor A, Glick A, Soreq H (1999) Structural roles of acetylcholinesterases variants in biology and pathplogy. Eur J Biochem 264: 672-686.

Hecht JR (1998) Gastrointestinal toxicity of irinotecan. Oncology 12: 72-78. 
Hyatt JL, Tsurkan L, Morton CL, Yoon KJP, Harel M, Brumshtein B, Silman I, Sussman JL, Wadkins RM, Potter PM (2005) Inhibition of acetylcholinesterase by the anticancer prodrug CPT-11. Chem Biol Interact 157/158: 247-252.

IAEA (2001) Cytogenetic Analysis for Radiation Dose Assessment. A manual. International Atomic Agency Technical Report Series 405, pp 27-37. IAEA, Vienna,

Jonson MK, Jacobsen D, Meredith TJ, Eyer P, Heath AJ, Ligtenstein DA, Marrs TC, Szinicz L, Vale JA, Haines JA (2000) Evaluation of antidotes for poisoning by organophosphorus pesticides. Emerg Med 12: 22-37.

Kassa J, Cabal J, Bajgar J, Szinicz L (1997) The choice: HI6, pralidoxime or obidoxime against nerve agent? ASA Newslett 97: 16-18.

Kopjar N, Želježić D, Lucić Vrdoljak A, Radić B, Ramić S, Milić M, Gamulin M, Pavlica V, Fučić A (2007) Irinotecan toxicity to human blood cells in vitro - relationships between various biomarkers. Basic Clin Pharmacol Toxicol 100: 403-413.

Massoulié J, Anselmet A, Bon S, Krejci E, Legaly C, Morel N, Simon S (1999) The polymorphism of acetylcholinesterase: post-translation processing, quaternary associations and localization. Chem Biol Interact 119/120: $29-42$.

Mesić M, Deljac A, Deljac V, Binenfeld Z (1991) Reactivators of acetylcholinesterase inhibited by organophosphorus compounds. Imidazole derivatives II. Acta Pharm 41: 203-210.

Møller P, Knudsen LE, Loft S, Wallin H (2000) The comet assay as rapid test in biomonitoring occupational exposure to DNA-damaging agents and effect of confounding factors. Cancer Epidemiol Biom Prev 9: 1005-1015.

Mortensen SR, Brimijoin S, Hoper MJ, Padilla S (1998) Comparison of the in vitro sensitivity of rat acetylcholinesterase to chlorpyrifos-oxon: what do tissue $\mathrm{IC}_{50}$ values represent? Toxicol Appl Pharmacol 148: 46-49.

Morton CL, Wadkins RM, Danks MK, Potter PM (1999) The anticancer prodrug CPT-11 is a potent inhibitor of acetylcholinesterase but is rapidly catalysed to $\mathrm{SN}-38$ by butyrylcholinesterase. Cancer Res 59: 1458-1463.

O'Conor PS, Mumma JV (1985) Atropine toxicity. Am J Ophtalmol 99: 613-614.

Petit RG, Rothenberg ML, Mitchell EP, Compton LD, Miller LL (1997) Cholinergic symptoms following CPT-11 infusion in a phase II multicenter trial of $250 \mathrm{mg} / \mathrm{m}^{2}$ irinotecan (CRT-11) given every two weeks. Proc Annu Meet Am Soc Clin Oncol 16: A953.

Rothenberg ML, Kuhn JG, Burris H, Nelson J, Eckardt JR, Tristan-Morales M, Hilsenbeck SG, Weiss GR, Smith
LS, Rodriguez GL (1993) Phase I and pharmacokinetic trial of weekly CPT-11. J Clin Oncol 11: 2194-2204.

Sheridan RD, Beeson D, Tattersall JEH (2000) Non-competitive block of the human muscle adult nicotinic acetylcholine receptor ion channel by the bispyridinium compounds, SAD-128 (SAD), toxogonin (TOX) and HI6. Eur J Neurosci 12 (Suppl S): 36.

Singh NP (2000) Microgels for estimation of DNA strand breaks, DNA protein crosslinks and apoptosis. Mutat Res 455: 111-127.

Singh NP (2003) Apoptosis by DNA diffusion assay. In: Methods in Molecular Medicine - Chemosensitivity (Blumenthal R, ed) pp 78-94. Humana Press, New York.

Singh NP, McCoy MT, Tice RR, Schneider EL (1988) A simple technique for quantitation of low levels of DNA damage in individual cells. Exp Cell Res 175: 184-191.

Somani SM, Romano JA Jr (2001) Chemical Warfare Agents: Toxicity at low Levels. CRS Press LLC, Boca Raton, Florida.

Surralles J, Xamena N, Creus A, Catalan J, Norppa H, Marcos R (1995) Induction of micronuclei by five pyrethroid insecticides in whole-blood and isolated human lymphocyte cultures. Mutat Res 341: 169-184.

Tattersall JEH (1993) Ion channel blockade by oximes and recovery of diaphragm muscle from soman poisoning in vitro. Br J Pharmacol 108: 106-115.

Taylor P, Radić Z (1994) The cholinesterases: from genes to proteins. Annu Rev Pharmacol Toxicol 34: 281-320.

Tice RR, Agurell E, Anderson D, Burlinson B, Hartmann A, Kobayashi H, Miyamae Y, Rojas E, Ryu JC, Sasaki YF (2000) Single cell gel/comet assay: guidelines for in vitro and in vivo genetic toxicology testing. Environ $\mathrm{Mol}$ Mutagen 35: 206-221.

Tobin P, Rivory L, Clarke S (2004) Inhibition of acetylcholinesterase in patients receiving irinotecan (Camptothecin-11). Clin Pharmacol Ther 76: 503-510.

US Patent 5916903 (1999) Method for reducing the effects of antineoplastic disease treatment. www.freepatentsonline.com/5916903.html (Accesion date: February, 14th, 2007).

Waadkins RM, Hyatt JL, Yoon KJ, Morton CL, Lee RE, Damodaran K, Beroza P, Danks MK, Potter PM (2004) Discovery of novel selective inhibitors of human intestinal carboxylesterase for the amelioration of irinotecan-induced diarrhea: synthesis, quantitative structureactivity relationship analysis, and biological activity. Mol Pharmacol 65: 1336-1343. 